\title{
SAORES: a spatially explicit assessment and optimization tool for regional ecosystem services
}

\author{
Haitang Hu $\cdot$ Bojie Fu $\cdot$ Yihe Lü $\cdot$ Zhenmin Zheng
}

Received: 31 May 2014/Accepted: 21 November 2014/Published online: 2 December 2014

(C) Springer Science+Business Media Dordrecht 2014

\begin{abstract}
Context The concept of ecosystem services (ES) has become mainstreamed in environmental planning and management recently, and with that various tools for quantifying ecosystem services have emerged. However, designing the tools for integrated assessment and optimization of multiple ES has become a challenging task.

Objectives In order to promote the efficiency of ecosystem planning and management, we develop a spatial decision support tool named SAORES, which provides a platform for exploratory scenario analysis and optimal planning design, rather than ES assessment. Method SAORES is formed with four modules: the scenario development module, the integrated ecosystem service model base, the ecosystem service tradeoff analysis module, and the multi-objective spatial optimization module based on NSGA-II. Using SAORES, we make a case study on the Yangou catchment of the Loess Plateau, China. Based on impact assessment of the Grain to green program (GTGP), we optimize the farmland retiring planning, involving multiple objectives which include the ecocompensation and the key ES.
\end{abstract}

H. Hu · B. Fu ( $\varangle) \cdot$ Y. Lü $\cdot$ Z. Zheng

State Key Laboratory of Urban and Regional Ecology,

Research Center for Eco-Environmental Sciences,

Chinese Academy of Sciences,

P. O. Box 2871, Beijing 100085,

People's Republic of China

e-mail: bfu@rcees.ac.cn
Results The integrated assessment shows that, the aim of the GTGP, the water and soil retention are prominent improved. Optimization for GTGP provides a series of optimal solutions, which are better than other single optimized solutions, and are twice the cost-effectiveness of the actual situation.

Conclusions SAORES, as a decision support tool, can improve the scenario analysis and multi-objective optimal planning design for ecosystem management and planning. The case study demonstrates the potential and effectiveness of SAORES and spatial multi-objective optimization model for ecosystem service management, especially in the Loess Plateau.

Keywords Ecosystem services - Ecosystem service assessment $\cdot$ Decision support tool $\cdot$ Ecosystem management $\cdot$ Multi-objective optimization $\cdot$ Spatial optimization

\section{Introduction}

Studies on ecosystem services (ES) indicating the benefits people obtain from nature have increased dramatically since the late 1990s (Daily 1997; Costanza et al. 1997; MA 2005; Daily et al. 2010; Groot et al. 2010). It is acknowledged that the conceptual framework of ecosystem services could be applied to ecosystem management to improve the decision making for land use planning (Daily et al. 2009; 
Wainger et al. 2011). The ecosystem service has been mainstreamed into environmental planning and management (Groot et al. 2010; Daily et al. 2010).

With the rapidly growing of theoretical research on ecosystem services and applications, all sorts of tools have emerged, including InVEST (Tallis et al. 2013), ARIES (Bagstad et al. 2011), MIMES (Boumans and Costanza 2007), EcoAIM (Waage et al. 2011), LUCI (formerly Polyscape, Jackson et al. 2013), EcoMetrix (Parametrix 2010), ESR (World Resources Institute (WRI) 2012), Envision (Guzy et al. 2008) and EcoServ (Feng et al. 2011), which mainly focus on the quantification and valuation of ES (Bagstad et al. 2013). ES studies should encompass all of the components including ecological structures and processes, ecosystem services, land-use decisions, and the dynamic feedback between them as shown in Fig. 1 (Liu et al. 2010). The general spatial explicitly ES assessment tools have built the relationship between landscape structure and ecosystem services. Assessment is important, but not enough for landscape planning. There are some key deficits causing insufficient use of ES concept in ecosystem management, including lack of (1) integrated modeling, (2)feedbacks and trade-offs, (3) combining scenario analysis with explorative modelling (Volk 2013). Seppelt et al. (2013) confirm that there is an urgent need for improved methods to combine trade-off analysis and optimization with scenario analysis, for explorative modeling to obtain more efficient solution. Accordingly, the tool should make the planning design alternatives accessible for decision making and evaluate the response of these alternatives by the relative assessment models. Furthermore, it should

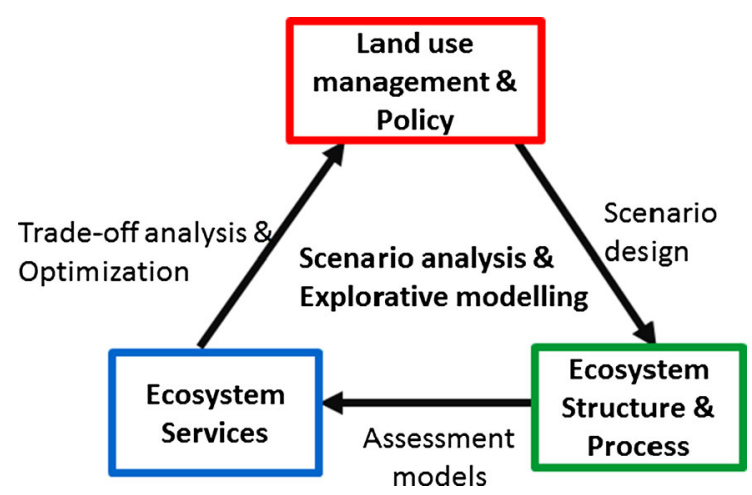

Fig. 1 A framework for integrated assessment and optimization of ecosystem services into land use management (adapted from Liu et al. 2010) provide trade-off and multi-objective optimization methods for creating and selecting optimal solutions. This is absolutely essential and challenging in ecosystem planning and management (Groot et al. 2010). Scenario analysis provides the information on the dependency of selected factors or services and their mix. However, the possible trade-off relationship between ecosystem services makes it difficult to design optimal options. A functional understanding of feedbacks between landscape and management is required, which can be achieved by linking models with multi-objective optimization algorithms, which combine the assessment of ecosystem functions and search through the space of possible, spatially explicit, management options (Seppelt et al. 2013). NatureServe Vista (NatureServ 2013) is a landscape-level assessment and planning tool for conservation planning. But for ecosystem management, especially landscape management and planning, this kind of tool is still scarce.

Multi-objective optimization is defined by Osyczka (1985) as a problem of searching for a vector of decision variables that satisfy the restrictions and optimize the objective functions; that is, to find the solutions that express optimal trade-offs between the multiple conflicting objectives. This approach has been used for decades and has been introduced into solving spatial problems in recent years (Ducheyne et al. 2006; Roberts et al. 2011; Cao et al. 2011; Fotakis et al. 2012; Jankowski et al. 2014). The multi-objective spatial optimization methods are well-suited to explore the trade-off and synergy relationships between ecosystem services (Groot and Rossing 2011). By adopting multi-objective optimization methods, stakeholders can compare the outcomes, evolve new scenarios adaptively and prioritize the solutions that maximize ecosystem services. This might be a feasible solution for promoting the efficiency of ecosystem management. To meet the requirements of ecosystem management, we have designed and developed an integrative assessment and optimization tool for ESoriented ecosystem management.

In this paper, we present SAORES: spatial assessment and optimization tool for regional ecosystem services, a novel decision support tool for spatially explicit regional ecosystem management and planning. It focuses on integrative assessment and optimization of ecosystem services, especially for the ecological restoration and management of the Chinese Loess Plateau. 
The outline of the remainder of the paper is as follows: "Framework of SAORES" section presents the framework of SAORES with a detailed description of each module, and the methodology of the multiobjective optimization was used in the optimization module. This is followed by a case study on the Yangou catchment of the Loess Plateau, aiming at the optimization of the largest ecological restoration project in China, which is illustrated in "Case study: assessment and optimization of ES in the Yangou catchment of the Chinese Loess Plateau" section. Finally, we present the discussion and future research directions.

\section{Framework of SAORES}

The creation of SAORES was driven by the needs of current ecosystem management research under the framework of ecosystem services. In service-based ecosystem management research, the general approach includes stages such as service identification, scenario development, ecosystem services assessment, integrated assessment and synthesis analysis (analysis and reporting of comprehensive scenario impacts on ES and trade-offs between ES), and ecosystem service-oriented management optimization. Aiming at the tool requirements in each phase mentioned above, and taking into account serviceoriented optimization for ecosystem management as the ultimate goal, the SAORES provides not only the model base for quantifying multiple ES, but also includes the functions of scenario design, trade-off analysis and multi-objective spatial optimization.

SAORES is formed with four modules: the scenario development module, the integrated ecosystem service model base, the ES trade-off analysis module, and the multi-objective optimization module. It is developed using C\# language, based on a well-known GIS developer kit, ArcGIS Engine (www.esri.com/ software/arcgis/arcgisengine). The framework of SAORES is outlined in Fig. 2. A brief introduction about function for module is as follows:

The scenario development module is used to construct the spatially explicit scenarios, according to the customized rules, by imitating the various design modes of land use or ecosystem management policy and spatializing the corresponding planning allocation.
The ecosystem service model base provides an assessment of key ecosystem services for our study area at present, with integration of the multiple spatially explicit models, under the scenarios constructed by the scenario development module or the status quo.

The trade-off analysis module, based on the quantification of ES and the results of different scenarios, performs the trade-off analysis between and among multiple ecosystem services, explores the spatial interaction of ES between and among neighboring regions, and compares the benefit efficiencies of different management policies.

The multi-objective optimization module, as the core module of SAORES, provides a multi-objective method to support the spatial optimization of decision making on regional ecosystem planning and management.

Below, we will give a detailed description for each module of SAORES.

\section{Scenario development module}

This module's purpose is to construct the scenarios driven by various environment management policies (especially concerning land use change and management), human activity, climate change, and to simulate the landscape pattern and dynamics. To simulate the policies of ecosystem management with different allocation strategies, it supports the scenario construction approaches, including threshold-zoning, sitespecific change identification, auto-allocation of land use, landscape dynamic-modeling and benefit-pursuing. Benefit-pursuing is a way of decision making based on the assessment results of ecosystem services and is different from ways based on some environmental factor indices. It is a results-oriented approach.

According to the design modes of environment management policy, the scenarios development module supports:

(1) Scenario by assumption (planning)

(1.1) Site-specific: by clicking on map using a mouse or inputting the coordinates of extent using a keyboard, user can sketch a specific region and change its attributes of land use or land management.

(1.2) Threshold zoning: setting the thresholds of the key factors as zoning rules to change land use/management. 
Fig. 2 The framework of SAORES

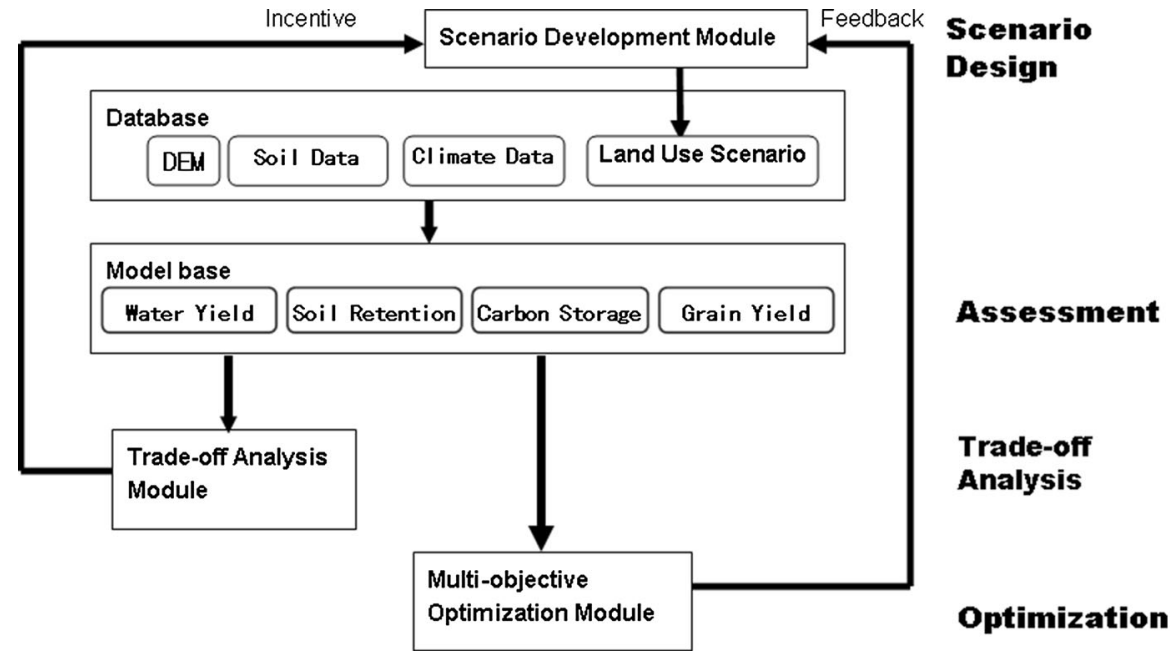

(2) Scenario by dynamic modeling: using land use change models or landscape dynamic models. At present, we only integrate CLUE-S (Verburg et al. 2002) to simulate land use dynamic. Given the land use structure or historical land use maps, the system will simulate the possible future land use allocation automatically.

(3) Benefit-pursuing:

(3.1) services-based zoning: selects the hotspots on the ecosystem service assessment maps.

(3.2) benefit criteria pursuing: defining the criteria or objectives of ecosystem service benefits, the system will design the optimized program using the single or multiple objective optimization method.

(3.3) cost-benefit criterion pursuing: defines the ratio criterion of ecosystem services benefit and the corresponding cost.

(3.1) is also a site-specific method, similar to (1.1), but based on the knowledge of the spatial patterns of ecosystem services. Moreover, (3.2) is different from (1.2) in that the former designs the thresholds according to the ecosystem services and the latter according to the environmental factors.

Integrated ecosystem service model base

The integrated ecosystem service model base provides the multiple ES assessment modeling environment with loose coupling. Herein, we select the prevalent models to assess the key ecosystem services for our study area, including water yield, soil retention, carbon storage, grain production. More models will be integrated into SAORES continually. This model base also provides various visualization modes, such as multi-window mapping/plotting, and a dynamic link between data and maps or plots, so as to allow for convenient exploration of the assessment results.

The water yield model is based on the Budyko curve and annual average precipitation (Budyko 1974), referring to the InVEST User's Guide (Tallis et al. 2013). The soil retention model refers the paper of Fu et al. (2011). The grain production is equal to the potential climate productivity (by Thornthwaite memorial model, Lieth and Box 1972) multiply a farmland natural quality grade index, which is determined by the factors such as soil quality, terrain, irrigation and drainage, according to The regulations of farmland grading (The Ministry of Land and Resources, PRC, 2003).

ES trade-off analysis module

The trade-off analysis module is a visualization and exploration tool to explicate the tradeoff relationship or interaction between multiple ecosystem services, based on the assessment of ESs. Through zoning statistics or sampling on the assessment maps of the multiple ES, we can prepare the data for further analysis. The tradeoff analysis can be made between the different sites on the same scenario, or between the 
different scenarios, especially driven by land use change. It displays the growth and decline of multiple ES using a flower diagram (Raudsepp-Hearne et al. 2010), shows the relationship between ES with the General QQ Plot (Johnston et al. 2001) or correspondence analysis (Zheng et al. 2014); explores the spatial association with the cross covariance cloud (Johnston et al. 2001); and identifies the interaction type by trade-off curve (Lester et al. 2013). These kinds of plots can assist users in identifying the trade-off relationship between multiple services.

\section{Multi-objective optimization module}

The multi-objective optimization module couples the ecosystem services assessment models and our modified multi-objective spatial optimization algorithm based on NSGA-II (the fast non-dominated sorting genetic algorithm-II, Deb 2001).

The NSGA-II is a widely used multi-objective optimization method (Cao et al. 2011), using an effective and fast-convergence elitist algorithm to search the final Pareto front, by applying a non-dominated ranking and crowding distance sorting method. Pareto front, or Optimality for multiple objectives, is a set of nondominated trade-off solutions which are better than all other solutions in at least one objective (Pareto 1896). The NSGA-II is widely applied in optimization of land use planning (Datta et al. 2007; Cao et al. 2011), forest planning (Fotakis et al. 2012), or spatial allocation of natural resources (Jankowski et al. 2014).

To achieve optimal spatial explicitly solutions under the framework of ecosystem service using NSGA-II, there are two key problems: algorithm spatialization and objective modeling. Objective modeling means to integrate the multiple ES assessment models to value the objectives. Most of the land use optimization researches use raster data as input (Stewart et al. 2004), for it is easier to formulate a spatial planning problem in mathematical terms. A chromosome, which means a scenario or solution, is represented a two-dimensional grid of genes, encoded with the land use type. The details about how to extend NSGA-II to multi-objective land use optimization can refer to the paper of Datta et al. (2007) and Cao et al. (2011).

Under grid-based ecological model-driven architecture, an improved NSGA-II was adopted to optimize the land use pattern for the multiple ecosystem

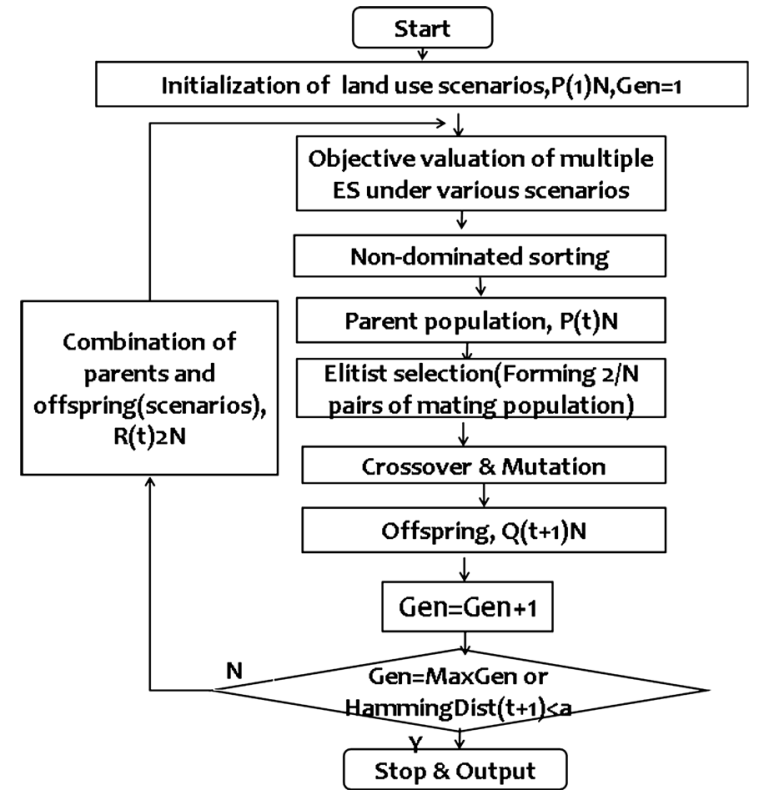

Fig. 3 Flow chart of NSGA-II for land use planning. Gen is the generation number. In $\mathrm{P}(\mathrm{t}) \mathrm{N}, \mathrm{P}$ is the parent population, $\mathrm{t}$ is the generation number, $\mathrm{N}$ is the size of population; $\mathrm{Q}(\mathrm{t}+1)$ is the new offspring population created from $\mathrm{P}(\mathrm{t})$ by selection, crossover and mutation operations; $\mathrm{R}(\mathrm{t})$ is the combination of $\mathrm{P}(\mathrm{t})$ and $\mathrm{Q}(\mathrm{t}+1)$, with size of $2 \mathrm{~N}$

services or other objectives and, subsequently, to realize the adaptive ecosystem management.

The flow chart of our NSGA-II algorithm for land use optimization is shown in Fig. 3. We can import the scenarios designed by scenario development module as initial parent population, and then value the objectives using related models. Through the operators such as sort, selection, crossover and mutation, the parent population will reproduce the next generation offspring population, and obtain the new parents. The execution will stop while the algorithm becomes convergence or reach the max generation.

In this section, we will introduce how to use this module to obtain the optimal solutions, i.e. Perato front, or the efficiency frontier, as Polasky et al. (2008) described. For users, there are four steps to complete an optimization:

(1) Prepare data: construct the initial scenarios using the scenario development module or other tools, and encode the scenarios;

(2) Define objectives and constraints;

(3) Select the models which quantify these objectives or constraints, set the parameters and import the data for these models; 
(4) Wait for the running of the optimization algorithm and outputting the results.

\section{Case study: assessment and optimization of ES in the Yangou catchment of the Chinese Loess Plateau}

Study area

The Yangou catchment is located in the middle of the Loess Plateau in Shaanxi Province, China, which is a subwatershed in Yanhe basin (Fig. 4). The climate is semiarid, with an average annual precipitation of $530 \mathrm{~mm}$. Aridity, rainstorms, hilly terrain, arenaceous soil, and poor vegetation cover make the Yangou catchment prone to serious water loss and soil erosion problems, especially after the wide-ranging sloping cropland development recently decades. To solve these problems, the Chinese government implemented a series of policies toward ecological restoration, among which the Grain to Green Program (GTGP), in force since 1999, is the largest farmland retirement program with public payment (Lü et al. 2012), in terms of area withdrawn from farming. The long-term effect of the GTGP has always been paid high attention. Since 2013, the Yan'an city (where just the Yangou catchment is located in) plans to start up the second phase of farmland retirement project.

With the implementation of the Grain to green program (GTGP), land use has been changed drastically in this area, especially since 2000. Land use maps for 1980, 2000, and 2008 show the land conditions at different stages of the GTGP (Fig. 5). The proportion of farmland retired from 2000 to 2008 is $31.4 \%$, much more than only $5 \%$ from 1980 to 2000 . Among the retired farmland, $0.5 \%$ converts to woodland, $3.6 \%$ to shrub, while $95.9 \%$ to grassland.

In the Yangou catchment, water retention, soil retention and grain production are the most important ecosystem services. We used our developed tool, SAORES, to assess these ecosystem services and optimize the planning of farmland retirement.

Application of SAORES and results

\section{Materials}

Land-use maps and 1:100,000 scale soil maps of Yangou and, were provided by the Institute of Soil and
Water Conservation, Chinese Academy of Sciences. DEM data were obtained from the National Fundamental Geographic Information System at a resolution of $25 \mathrm{~m}$. Climate data (1 km resolution) were downloaded from the thematic database for human-earth system (www.data.ac.cn).

\section{Assessment of ecosystem services}

With SAORES, the assessment of grain production, soil retention and water yield services for 1980, 2000 and 2008 is presented as Fig. 6. The results indicate that, from 2000 to 2008 , the $31.4 \%$ of farmland retired brings the $12.4 \%$ decrease for water yield and $9.1 \%$ increase for soil retention services, at the cost of the $26.4 \%$ grain production loss (2342t per year). The GTGP eco-compensation fund paying to local farmers is equal to 1,205 tons of grain per year for the 803 ha retired farmland in this region. This shows that the land use change, especially farmland retirement, has resulted in the reduction of soil erosion and water loss. The standard of eco-compensation, $1,500 \mathrm{~kg} \mathrm{ha}^{-1}$, is more than the net income (about $1,000 \mathrm{~kg} \mathrm{ha}^{-1}$ not considering labor cost) from the retired poor farmland, for which productivity is only about $3,400 \mathrm{~kg} \mathrm{ha}^{-1}$.

\section{Spatial multi-objective optimization planning for GTGP}

In order to promote the efficiency of the GPGT policy and pursue the maximization of these important ecosystem services, we design the spatial optimization planning for retired farmland. The study area is divided into a regular two-dimensional grid at a resolution of $25 \mathrm{~m}$. Each grid represents one unit of a landscape as a gene in the optimization algorithm, coded according to the land-use type. In order to eliminate the impact of climate change on these objectives, we used the climate data of the year 1998 (a year with common climatic condition in this region) in the model calculation for all the scenarios. With the application of SAORES, we optimized the allocation of retired farmland in this region with 70,871 planning units, based on an assessment and trade-off analysis of these three kinds of ecosystem services:

First, the initial populations (solutions) for NSGA algorithm were created. The size of populations we adopted is 20 , to assure the diversity of populations, the balance of the high computational demand of 
Fig. 4 Location of the study area
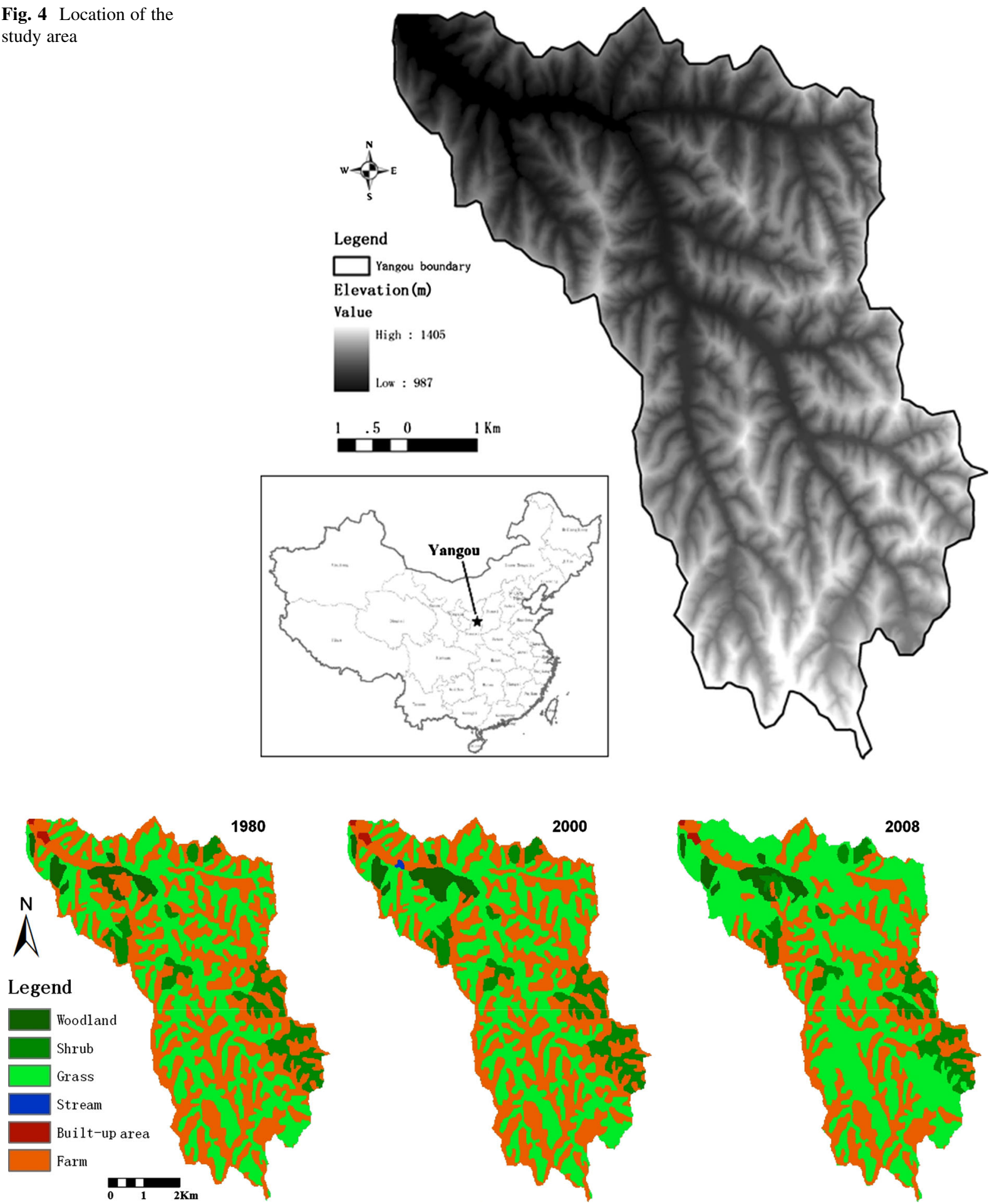

Fig. 5 Land use maps of the Yangou catchment at the earlier (1980), early (2000) and late stages (2008) of GTGP 


४Fig. 6 Assessment of ecosystem services (the top, middle and bottom are respectively for grain production, soil retention and water yield)

assessment models, and the quality of the trade-off solutions. The diversity of the initial population is important to insure the optimization process is stable and unbiased. In this paper, we create the initial population by service-threshold zoning based on the assessment of ecosystem services, as well as the historical and existing land use status, or the rulebased zoning with relevant factors. The 20 initial populations designed came from these three modes of scenarios building, as follows:

(I) Historical status quo: (1) 1980s land use map; (2) 2000s land use map; (3) 2008s land use map;

(II) Factor threshold (threshold determination based on the value of the important factors which impact the related ecosystem services): (4) retiring the farmland with slopes above $10^{\circ}$ to grassland; (5) retiring the farmland with slopes above $15^{\circ}$ to grassland; (6) or woodland; (7) or shrub; (8) retiring the farmland with slopes above $25^{\circ}$ to grassland; (9) or woodland; (10) or shrub;

(III) Service threshold (threshold determination based on the value of the related ecosystem services): (11) retiring the farmland with grain production per ha under $3,750 \mathrm{~kg}$; (12) or $4,200 \mathrm{~kg}$; (13) or 4,500 kg; (14) or 5,250 kg; (15) or $6,000 \mathrm{~kg}$; (16) retiring the top $25 \%$; or (17) $50 \%$ farmland on soil erosion severity; (18) retiring the bottom $25 \%$; or (19) $50 \%$ farmland on soil retention; (20) retiring the top $25 \%$ farmland on water yield.

These 20 initial scenarios are built (Fig. 7) using the scenario development module of SAORES, based on the assessment of the multiple ecosystem services by the "Integrated ecosystem service model base" module..

Second, we defined the objectives and constraints according to the goal of the GPGT project and the characteristics of the Yangou catchment. At first, four optimization objectives we identified were to maximize soil retention services and grain production services, and minimize water yield services and eco-compensation for retired farmland. Moreover, we assumed that the food production should be selfsufficient, or the income from crop farming could provide the basic living security for the agricultural populations and make it as a constraint of the optimization. This multi-objective optimization problem, which involves four ecosystem service objectives, is formulated as follows:

$$
\begin{aligned}
& \text { Maximize }\left(S_{\text {retention }}, G_{P}\right) \\
& \text { Minimize }\left(Y_{\text {total }}, C_{\text {ecocomp }}\right) \\
& \text { Subject to } \mathrm{G}_{\mathrm{P}}>\mathrm{P}_{\mathrm{pop}} \times 400 \mathrm{~kg}
\end{aligned}
$$

where $Y_{\text {total }}$ represents the total water yield for whole region, $S_{\text {retention }}$ represents the total soil retention, $G_{P}$ represents the total grain production, $C_{\text {ecocomp }}$ is the total eco-compensation, and $P_{p o p}$ is the local population.

Next, we selected the models, that is, the objective functions, for the above three ecosystem services and the eco-compensation.

After that the modified NSGA-II model was executed for no more than 1,000 generations to optimize the above objectives subject to the constraint.

Finally, the results of optimization were analyzed. Figure 8 maps one of the optimized solutions. From it we can see that the optimized solution is much more fragmentized than historical land use maps, to utilize the spatial heterogeneity of ecosystem services fully. Figure 9 shows the objectives assessment results of the 20 initial scenarios and the 20 optimized solutions which are on the Pareto front.

From Fig. 9, we can see the trade-off relationship between the four objectives. The grain yield shows a synergy with water yield service and a trade-off with soil retention. It is obvious that the distribution of initial scenarios is dispersive. We are careful to ensure the diversity of the initial solutions, e.g., emphasis on the soil retention, or grain production, or from the slope factor, and so on. Although slope is the most important factor for all of the three ecosystem service objectives in this region, the relationship between them is nonlinear. Solutions with different designs of spatial allocation bring very different results, even with similar retired areas. This kind of complicated interaction between the objectives is the basis of the existence of the multi-objective optimization. By trading off the effectiveness of multiple objectives grid by grid with the whole benefit between different 
(1)

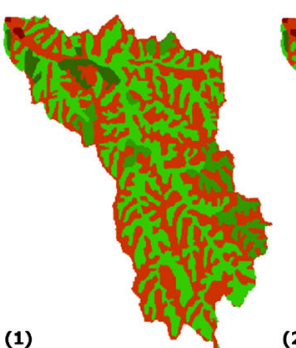

(6)

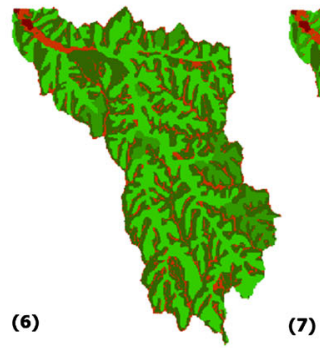

(7)

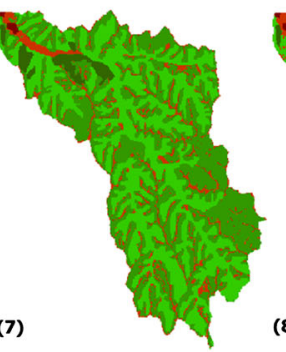

(8)



(11)

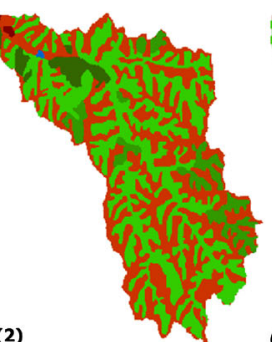

(3)

(13)

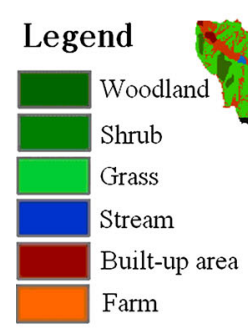

(16)

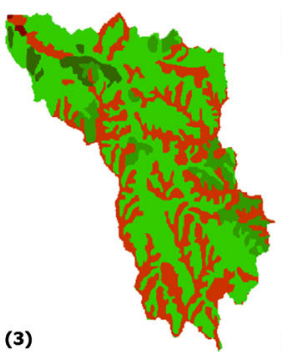

(4)

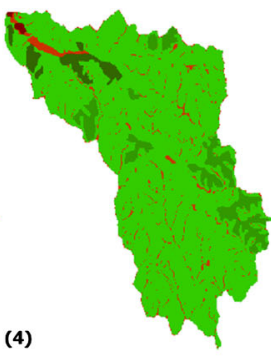

(5)
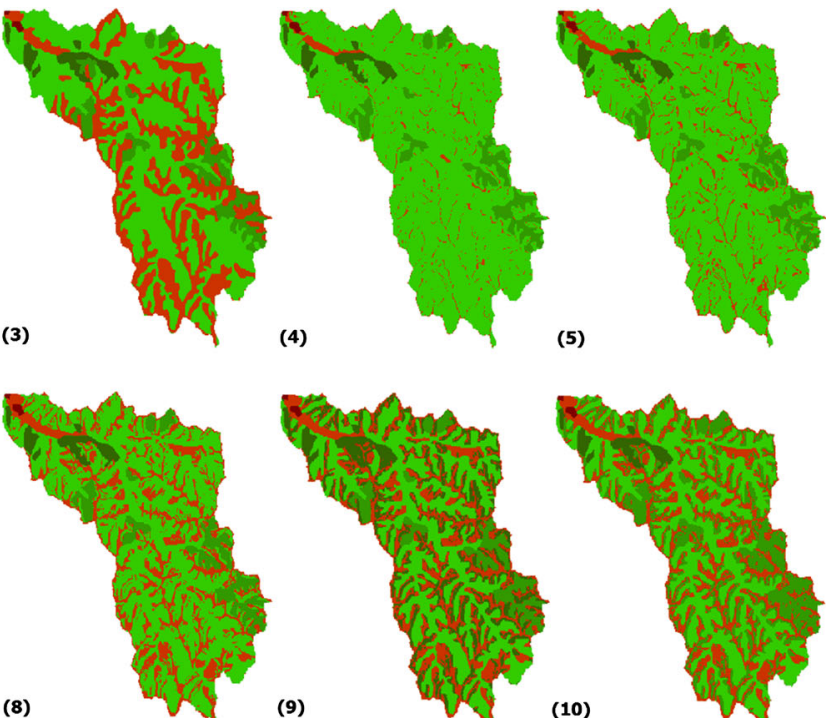

(9)
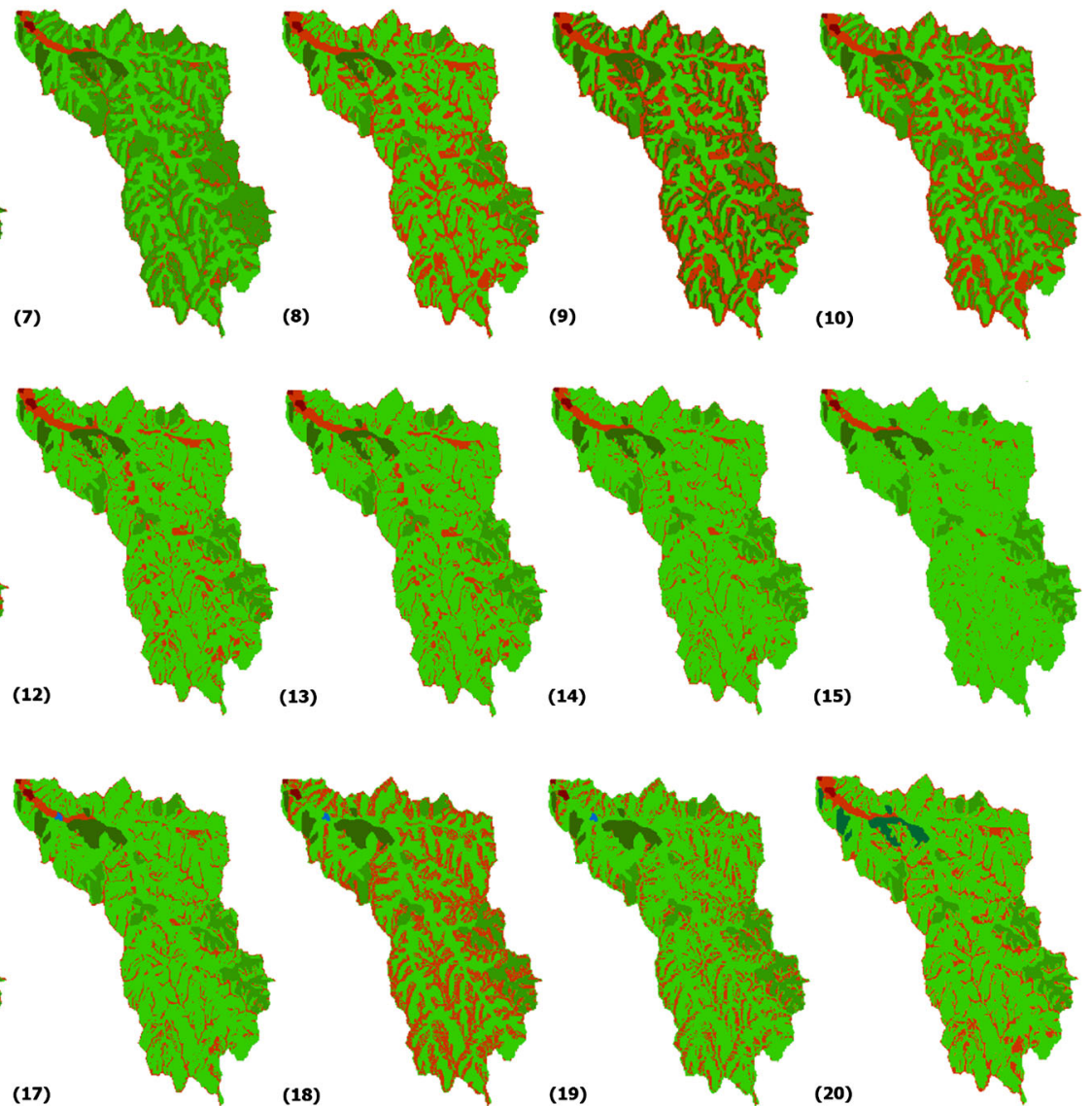

(18)
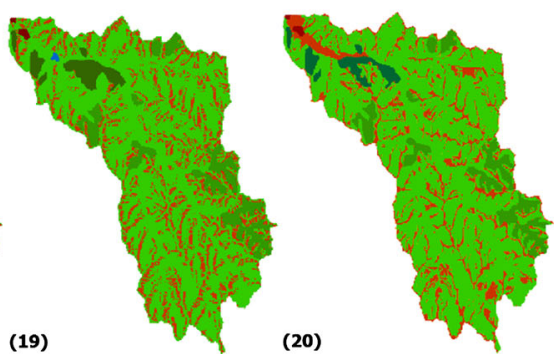

Fig. 7 Initial scenarios for GTGP. The sequence number for each scenario is in accordance with the number in the context about the 20 initial scenarios building

solutions, searching for Pareto-optimal solutions in spatial optimization is to make it efficient.

Through the step-by-step iterations, the generation approaches the overall optimization for all four objectives, ultimately reaching a convergence. For the solutions with the same retirement area or grain loss, optimized solutions have better water/soil retention effects than most initial ones. For example, solution " 107 " with the similar retirement area (i.e., the same eco-compensation) of solution " 3 " which is the actually scenario of year 2008 (referring the bottom plots of Fig. 9), brings the decrease of $24 \%$ for water yield and the increase of $17.7 \%$ for soil retention, which about doubles that of 2008. Solution "116" with similar water yield and soil retention as solution " 3 ", provides an increase of $14.9 \%$ for grain yield and a decrease of $47.4 \%$ for the retiring area and ecological compensation compared to 2008 (solution " 3 "). An interesting phenomenon is that the solution " 2 ", "6" are just at the two ends of the Pareto front 




Fig. 8 Land use map for one of the optimized solutions

line. Assuming this isn't caused by the limitation of the optimization algorithm, perhaps we could draw the conclusion that, land use change without policy interrupt may be led to an optimal scheme by longterm natural selection. Solution " 6 ", retiring the farmland with slopes above $15^{\circ}$ to wood land, is a nice solution balancing these four objectives, which is just the solution of second-phase farmland retirement project of Yan'an. These conclusions are true or false, needing further study and demonstration. Furthermore, it is notable that most of the initial solutions, besides the solution "9", "2" and "6", are behaves well on water yield objective (at the upper of the Pareto front), while their soil retention objective value are obviously lower than the Pareto front. Solution "9" is quite different with them. This means that retiring the farmland with a slope above $25^{\circ}$ to woodland is an optimal solution while the decision makers take the soil retention as the most important service.

\section{Discussion and future work}

With the rapid growth for ES studies, ecosystem service has become mainstreamed in ecosystem management. In order to make full use of ES concept and promote the efficiency of environmental management, we develop a new tool, SAORES, which provides an exploratory spatial decision support environment for ecosystem management and planning, supporting for scenario building, trade-off analysis, and multi-objective optimal planning design, rather than ES assessment.

SAORES is developed especially for our study in the Loess Plateau, China, where the largest ecological restoration project GTGP had carried out about 15 years ago. In addition to the assessment of ecosystem services, the characteristic of this tool is that it can assist to build the scenarios by the general modes of planning design, make trade-off analysis based on assessment. Furthermore, it can optimize ecosystem management by providing a set of Paretooptimal solutions using a modified spatially explicit multi-objective optimization algorithm, NSGA-II. In this paper, we display how the SAORES works on the Yangou catchment case study. With SAORES, users can study what changes happened on the key ecosystem services in this area, the trade-off relationship between them, the efficiency of the project. Furthermore, they can design various scenarios for single objective optimal or key factor rule-based, make scenario analysis and obtain the multi-objective optimal solutions for GPGT planning.

Analysis based on assessment shows that, the aim of the GTGP, the water and soil retention are prominent improved. The compensation for local farmers is much higher than the net income obtained from farming on the retired farmland with low grain productivity. This makes it easy for local farmers to accept the GTGP. At the same time, this increases the burden of government. Integrated assessment under the framework of ES provides a way to balance the relationship between economic developments, ecological restoration and government invest.

Optimization planning for GTGP in the case study demonstrates the potential and effectiveness of the spatial multi-objective optimization module of SAORES. The optimized solutions improve the efficient comparing the 20 initial scenarios, including historical status quo and simple designed solutions. For example, comparing the optimized solution and the actual situation, which with the same management cost, just by optimizing the spatial allocation of policy implementation, the ecosystem services can be clearly 

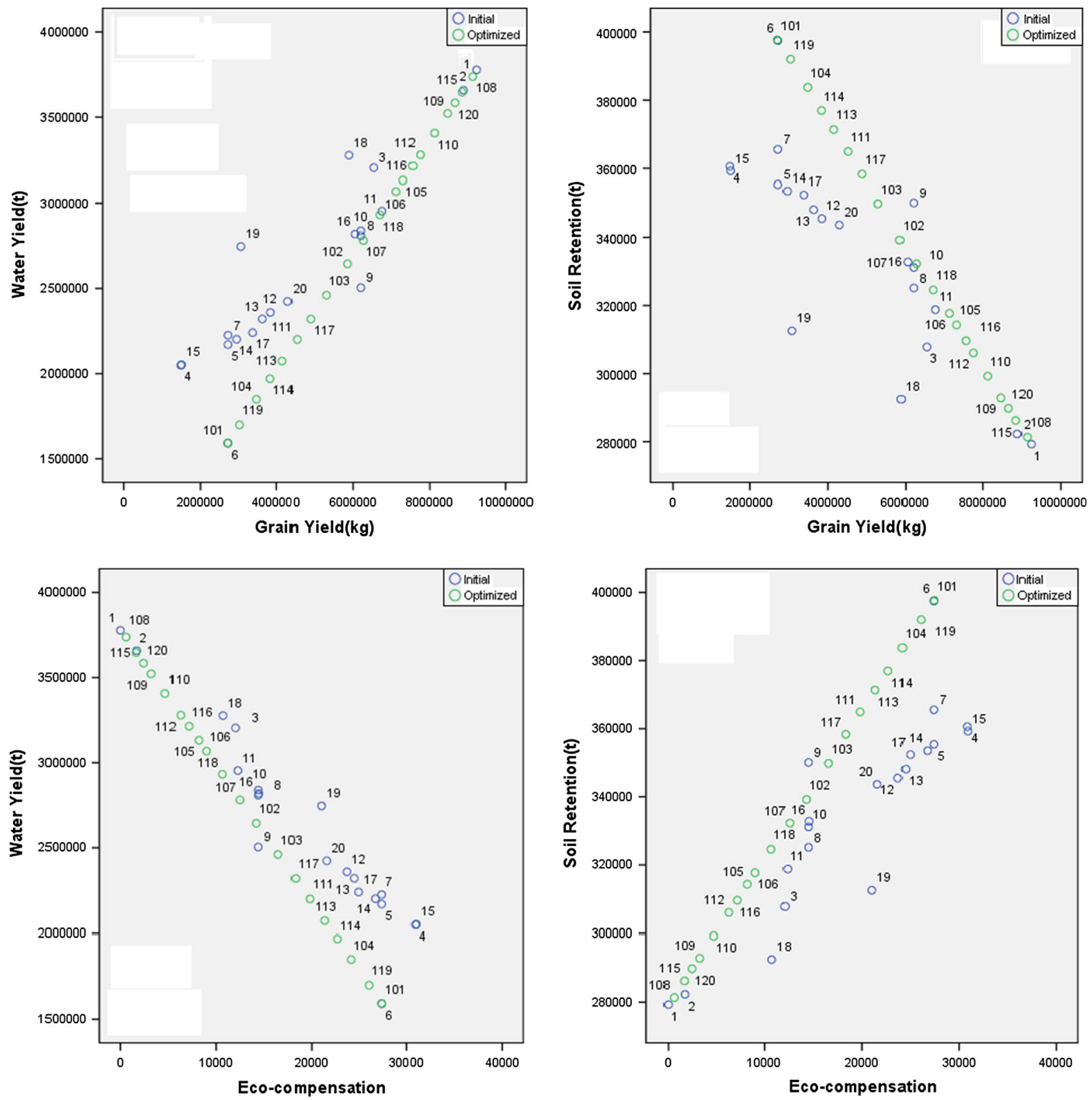

Fig. 9 The multi-objective assessment for the initial and optimized solutions. The blue dots are initial solutions, and the green ones are optimized ones. The dots labeled with 1-20 correspond to the serial numbers for the initial scenarios listed

above, as well as the ones with 101-120, meaning the optimized solutions. The eco-compensation is represented by the area of the retired farmland

enhanced. This indicates that the spatiality is indispensable in the ecosystem management. Therefore, considering spatial characteristic is important in ecosystem management planning (Polasky et al. 2008).

Moreover, our multi-objective optimization model involves economic costs of management activities as

one objective, in addition to the objectives for provision of the ecosystem services. This is good for trading-off the economic pay and ecosystem services return, and optimizing the cost-effectiveness. Thus, SAORES can improve the efficiency and effectiveness of ecosystem management under the complicated conditions of interacting spatial-dependent objectives. 
On the other hand, the optimization results offer not only one optimal solution, but a series of optimal solutions with a symmetrical distribution on the Pareto front curve. Therefore, the users or policy-makers can select their solution from the list of Pareto-optimal solutions, according to the manager's preference: the funds available, the goal for some kind of ecosystem service, the highest cost-effect ratio, or a combination of all.

SAORES can be provided to the officials or researchers on ecosystem management in the Loess Plateau, to support spatial planning decision-making and policy design, aiming at an optimization of the integrated objectives for multiple ecosystem services and cost-effectiveness.

SAORES is still a developing tool. In order to enhance the extent and capabilities of SAORES, future work will include more models for other ecosystem services and add a new trade-off analysis function. Furthermore, to promote the landscape managementoriented optimization, we can consider the spatial cluster effect and involve the cost-benefit efficiency as a criterion in the optimization algorithms, and add the analysis plots in varied forms on optimization results. The other multi-objective optimization algorithms will be used to compare the performance of different methods.

With the development of ecosystem services and management, it is beyond doubt that ecosystem services will be embedded further into ecosystem management planning, and the spatial multi-objective optimization can be a bridge between them to solve this complex system management problem.

Acknowledgments This work was funded by the National Natural Sciences Foundation of China (No. 41230745) and the CAS/SAFEA International Partnership Program for Creative Research Teams of "Ecosystem Processes and Services".

\section{References}

Bagstad KJ, Villa F, Johnson G, Voigt B (2011) ARIES-artificial intelligence for ecosystem services: a guide to models and data, version 1.0 beta. The ARIES Consortium, Bilbao

Bagstad KJ, Semmens DJ, Waage S, Winthrop R (2013) A comparative assessment of decision-support tools for ecosystem services quantification and valuation. Ecosyst Serv 5:27-39

Boumans R, Costanza R (2007). The multiscale integrated Earth Systems model (MIMES): the dynamics, modeling and valuation of ecosystem services. Global assessments: Bridging scales and linking to policy. Report on the joint TIAS-GWSP workshop held at the University of Maryland University College Adelphi, USA, 10 and 11 May, GWSP issues in Global Water System Research, no. 2 (Vol. 2), (pp: 102-106). Bonn: GWSP IPO

Budyko MI (1974) Climate and life. Academic Press, San Diego

Cao K, Batty M, Huang B, Liu Y, Yu L, Chen J (2011) Spatial multi-objective land use optimization: extensions to the non-dominated sorting genetic algorithm-II. Int J Geogr Inf Sci 25(12):1949-1969

Costanza R, d'Arge R, De Groot RS, Farber S, Grasso M, Hannon B (1997) The value of the world's ecosystem services and natural capital. Nature 387(15):253-260

Daily GC (1997) Nature's services: societal dependence on natural ecosystems. Island Press, Washington, pp 1-49

Daily GC, Polasky S, Goldstein J, Kareiva PM, Mooney HA, Pejchar L, Ricketts TH, Salzman J, Shallenberger R (2009) Ecosystem services in decision making: time to deliver. Front Ecol Environ 7(1):21-28

Daily GC, Kareiva PM, Polasky S, Ricketts TH, Tallis H (2010) Mainstreaming natural capital into decisions. Oxford University Press, Oxford, pp 3-14

Datta D, Deb K, Fonseca CM, Lobo FG, Condado PA, Seixas J (2007) Multi-objective evolutionary algorithm for land use management problem. Int J Comput Intell Res 3(4):371-384

De Groot RS, Alkemade R, Braat L, Hein L, Willemen L (2010) Challenges in integrating the concept of ecosystem services and values in landscape planning, management and decision making. Ecol Complex 7(3):260-272

Deb K (2001) Multi-objective optimization using evolutionary algorithms. Wiley, Chichester

Ducheyne EI, De Wulf RR, De Baets B (2006) A spatial approach to forest-management optimization: linking GIS and multiple objective genetic algorithms. Int J Geogr Inf Sci 20(8):917-928

Feng M, Liu S, Euliss NH Jr, Young C, Mushet DM (2011) Prototyping an online wetland ecosystem services model using open model sharing standards. Environ Model Softw 26(4):458-468

Fotakis D, Sidiropoulos E, Myronidis D, Ioannou K (2012) Spatial genetic algorithm for multi-objective forest planning. For Policy Econ 2012(21):12-19

Fu BJ, Liu Y, Lu YH, He CS, Zeng Y, Wu BF (2011). Assessing the soil erosion control service of ecosystems change in the Loess Plateau of China. Ecol Complex 8(4):284-293

Groot JCJ, Rossing WAH (2011) Model-aided learning for adaptive management of natural resources - an evolutionary design perspective. Methods Ecol Evol 2:643-650

Guzy MR, Smith CL, Bolte JP, Hulse DW, Gregory SV (2008) Policy research using agent based modeling to assess future impacts of urban expansion into farmlands and forests. Ecol Soc 13(1):37

Jackson B, Pagella T, Sinclair F, Orellana B, Henshaw A, Reynolds B, McIntyre N, Wheater H, Eycott A (2013) Polyscape: a GIS mapping toolbox providing efficient and spatially explicit landscape-scale valuation of multiple ecosystem services. Landsc Urban Plan 112:74-88

Jankowski P, Fraleya G, Pebesma E (2014) An exploratory approach to spatial decision support. Comput Environ Urban Syst 45:101-113 
Johnston K, Ver Hoef JM, Krivoruchko K, Lucas N (2001) Using ArcGIS geostatistical analyst. ESRI Press, Redlands

Lester SE, Costello C, Halpern BS et al (2013) Evaluating tradeoffs among ecosystem services to inform marine spatial planning. Mar Policy 38:80-89

Lieth H, Box E (1972) Evapotranspiration and primary productivity. Thornthwaite memorial model. Publ Climatol 25(2):37-46

Liu S, Costanza R, Farber S, Troy A (2010) Valuing ecosystem services. Ann N Y Acad Sci 1185(1):54-78

Lü YH, Fu BJ, Feng XM, Zeng Y, Liu Y, Chang R, Sun G, Bingfang B (2012) A policy-driven large scale ecological restoration: quantifying ecosystem services changes in the Loess Plateau of China. PLoS One 7(2):e31782. doi:10. 1371/journal.pone.0031782

MA (Millennium Ecosystem Assessment) (2005) Current state and trends: synthesis. Island Press, Washington, pp 829-838

NatureServ (2013) NatureServe Vista: decision support for better planning. Available from: http://www.natureserve. org/conservation-tools/natureserve-vista. Accessed 12 Nov 2014

Osyczka A (1985) Computer aided multi-criterion optimization method. Adv Model Simul. AMSE Press 3(4):41-52

Parametrix (2010) An introduction to EcoMetrix: measuring change in ecosystem performance at the site scale. Parametrix, Portland

Pareto V (1896) Cours D'Economie Politique. Rouge, Lausanne

Polasky S, Nelson E, Camm J, Csuti B, Fackler P, Lonsdorf E, Montgomery C, White D, Arthur J, Garber-Yonts B, Haight R, Kagan J, Starfield A, Tobalske C (2008) Where to put things? Spatial land management to sustain biodiversity and economic returns. Biol Conserv 2008(141): 1505-1524

Raudsepp-Hearne C, Peterseon GD, Bennett EM (2010) Ecosystem service bundles for analyzing tradeoffs in diverse landscapes. Proc Natl Acad Sci USA 107:5242-5247

Roberts SA, Hall GB, Calamai PH (2011) Evolutionary multiobjective optimization for landscape system design. J Geogr Syst 13:299-326
Seppelt R, Lautenbach S, Volk M (2013) Identifying trade-offs between ecosystem services, land use, and biodiversity: a plea for combining scenario analysis and optimization on different spatial scales. Curr Opin Environ Sustain 5(5):458-463

Stewart TJ, Janssen R, van Herwijnen M (2004). A genetic algorithm approach to multiobjective land use planning. Computers and Operations Research 31(14):2293-2313

Tallis HT, Ricketts T, Guerry A, Wood SA, Sharp R, Nelson E, Ennaanay D, Wolny S, Olwero N, Vigerstol K, Pennington D, Mendoza G, Aukema J, Foster J, Forrest J, Cameron D, Arkema K, Lonsdorf E, Kennedy C, Verutes G, Kim CK, Guannel G, Papenfus M, Toft J, Marsik M, Bernhardt J, Griffin R (2013) InVEST2.5.3 User's Guide. The Natural Capital Project, Stanford

The Ministry of Land and Resources, PRC (2003) The regulations of farmland grading (TDPT 1004-2003). Standards Press of China, Beijing

Verburg PH, Soepboer W, Veldkamp A, Limpiada R, Espaldon V, Mastura SS (2002) Modeling the spatial dynamics of regional land use: the CLUE-S model. Environ Manage 30(3):391-405

Volk M (2013) Sustainability of water quality and ecology. Ecol Process 1(2):3-9

Waage S, Armstrong K, Hwang L (2011) New business decision-making aids in an era of complexity, scrutiny, and uncertainty: tools for identifying, assessing, and valuing ecosystem services. BSR, San Francisco

Wainger LA, King DM, Mack RN, Price EW, Maslin T (2011) Can the concept of ecosystem services be practically applied to improve natural resource management decisions? Ecol Econ 69(5):978-987

World Resources Institute (WRI) (2012) The corporate ecosystem services review: guidelines for identifying business risks and opportunities arising from ecosystem change, version 2.0. World Resources Institute, Washington

Zheng ZM, Fu BJ, Hu HT, Sun G (2014) A method to identify the variable ecosystem services relationship across time: a case study on Yanhe Basin, China. Landscape Ecol 29:1689-1696 